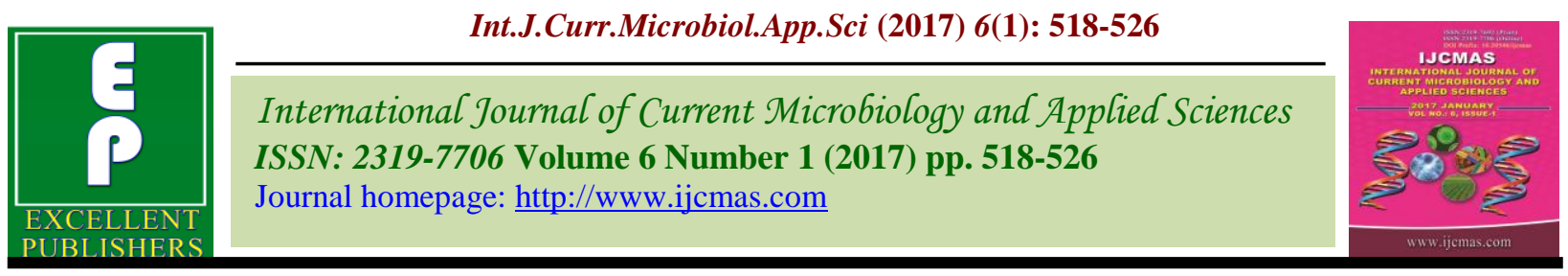

Original Research Article

http://dx.doi.org/10.20546/ijcmas.2017.601.062

\title{
Isolation of Bacterial Pathogens and Detection of MRSA and ESBL Producers causing Asymptomatic Bacteriuria in Antenatal Women
}

\author{
S. Hemalatha ${ }^{1}$, K.V. Leela ${ }^{1 *}$, Radhika Katragadda ${ }^{1}$, Thyagarajan Ravinder ${ }^{2}$, \\ P. Hema Suganya ${ }^{1}$ and S. Padmanaban ${ }^{3}$ \\ ${ }^{1}$ Department of Microbiology, Govt. Kilpauk, Medical College and Hospital, \\ Chennai- 600010, India \\ ${ }^{2}$ Department of Microbiology, Govt. Tiruvanamalai Medical College, Tiruvanamalai, India \\ ${ }^{3}$ NIIRH FU, ICMR, Govt. Kilpauk Medical college \& Hospital, Chennai- 600010, India \\ *Corresponding author
}

A B S T R A C T

Keywords

Asymptomatic

bacteriuria, Escherichia coli, Extended spectrum beta lactamases (ESBL), Methicillin resistant Staphylococcus aureus (MRSA).

Article Info

Accepted:

23 December 2016

Available Online:

10 January 2017
To isolate the bacterial pathogens causing asymptomatic bacteriuria in antenatal women,to study the drug resistance pattern and prevalence of MRSA and ESBL producers. Bacterial pathogens were isolated from 1000 urine samples collected from antenatal women following standard procedures. All the isolates were studied for antibiotic susceptibility pattern using modified Kirby bauer disc diffusion method. Resistant isolates were identified and studied for MRSA and ESBL by various methods. Out of 1000 urine samples culture positive were 118(11.8\%). E.coli was the predominant organism isolated 54 (45.76 \%).All Gram negative bacilli were 100\% sensitive to Piperacillin -tazobactam and Imipenem. All Gram positive cocci were $100 \%$ sensitive to Vancomycin and Linezolid. No MRSA was detected. Among the Enterobacteriaceae isolates, 6(8\%) were found to be ESBL producers. As asymptomatic bacteriuria is related to the complications in pregnancy, it is imperative that Urine culture tests should be done routinely for all the pregnant women to find out asymptomatic bacteriuria, and every positive case should be managed with appropriate antibiotics, to prevent any complication related to pregnancy.

\section{Introduction}

Urinary tract infections (UTI) are one of the most prevalent bacterial infections and the significant cause of morbidity and mortality (Shruthi et al., 2012; Raksha et al., 2003). Of all uncomplicated urinary tract infections, Escherichia coli are responsible for 50\%-90\% of infections. In pregnancy, urinary tract infections commonly occur, because of the physiological and morphological changes that occur in the genitourinary tract.
There are 2 types of urinary tract infection (UTI). They are asymptomatic and symptomatic urinary tract infection (Sujatha and Manju Nawani, 2014; Jayaseelan et al., 2013, Annie Rajaratnam et al., 2014). The definition of asymptomatic bacteriuria is the occurrence of actively multiplying bacteria, more than $10^{5}$ bacteria per $\mathrm{ml}$ of urine inside the urinary tract, exclusive of the distal urethra at a time when the patient has nil 
symptoms of UTI (Santogita Jain et al., 2013; Chandel Lata et al., 2012).

In pregnant women, the occurrence of asymptomatic bacteriuria was found to be $2 \%$ to $10 \%$ (Sudha Birader et al., 2013; Rajshekhar Kerure and Umashanker, 2013). Pregnancy increases the succession from asymptomatic bacteriuria to symptomatic bacteriuria which can cause acute pyelonephritis in 20 to $50 \%$ of cases and contributes to adverse perinatal outcomes like post partum hypertensive disease, urinary tract infections, anaemia, prematurity and increased fetal mortality rates if left untreated (Sujatha and Manju Nawani, 2014; Raul Raz, 2003; Graham and Galloway, 2001).

Asymptomatic bacteriuria is a microbial diagnosis. The gold standard test for asymptomatic bacteriuria is the urine culture. The relatively increased occurence of asymptomatic bacteriuria, the consequences faced by the antenatal women, the ability to avoid undesirable outcomes with the management justifies the testing of asymptomatic bacteriuria in pregnancy (Sujatha and Manju Nawani, 2014).

In different geographical regions, the frequency of the pathogen isolated and their antimicrobial resistance patterns can vary. Hence, the common etiological agents of asymptomatic bacteriuria should be investigated and their antimicrobial resistance pattern to be made aware of (Sujatha and Manju Nawani, 2014).

\section{Materials and Methods}

This cross sectional study was done for one year and six months from January 2014 to June 2015 to study the bacterial isolates causing asymptomatic bacteriuria in pregnancy at Government Kilpauk Medical College and Hospital, Chennai. Totally 1000 urine samples were collected from 18-40 years of age group among pregnant women and were studied during this period.

\section{Sample Collection and Transport (Sujatha and Manju Nawani, 2014)}

From 1000 asymptomatic antenatal women, urine specimens were collected by mid-stream clean catch method in a sterile container, which is wide mouthed and covered with tight fitting lids after obtaining informed consent. Specimens were transported immediately to the microbiology laboratory and processed without delay using standard procedures.

\section{Urine Culture}

\section{Semi-quantitative method (Kheya Mukherjee et al., 2014; Sushama Thakre et al., 2012; Gayathree et al., 2010)}

To isolate the organism, a semi-quantitative calibrated loop technique was used. One loopful of properly mixed urine that was not centrifuged was inoculated onto the surface of Nutrient agar, 5\% sheep Blood agar, Mac Conkey agar and Cysteine Lactose Electrolyte Deficient agar using a calibrated loop that delivers $0.01 \mathrm{ml}$ of urine sample. The culture plates were incubated under aerobic conditions at $37^{0} \mathrm{C}$ for $18-24$ hours. The colonies were counted using colony counter and the number of colony forming units were multiplied by 100 to find out the number of microorganisms present per millilitre of urine.

$\geq 10^{5}$ colony forming units/ml - significant bacteriuria.

The diagnostic criteria for asymptomatic bacteriuria was considered when atleast two consecutive urine samples showed more than or equal to $10^{5}$ colony forming units in $1 \mathrm{ml}$ of urine of the single species without any UTI symptoms (Lindsay Nicolle, 2003). To differentiate pathogens from commensals, 
standard microbiological methods were followed.

Antibiotic Susceptibility Testing (Niranjan and Malini, 2014; Bauer et al., 1996)

Antibiotic sensitivity testing was performed by the Kirby-Bauer's disc diffusion method using Mueller Hinton agar as per CLSI guidelines 2014(M100-S24).

The quality control strains used were
Staphylococcus aureus -

Escherichia coli

Pseudomonas aeruginosa -
ATCC 25923

ATCC 25922

ATCC 27853
Test to detect methicillin resistant Staphylococcus aureus Cefoxitin disc diffusion test (Anand et al., 2009)

The test was performed by placing $30 \mu \mathrm{g}$ of cefoxitin disc in the Mueller Hinton Agar plate without $\mathrm{NaCl}$ supplementation inoculated with test organism. The plate was kept in the incubator at a temperature of $37^{\circ} \mathrm{C}$. The zone of inhibition was determined after $24 \mathrm{hrs}$ and the zone size was interpreted as

Susceptible $-\geq 20 \mathrm{~mm}$

Resistant $\quad-\leq 19 \mathrm{~mm}$

Methods to Detect Extended Spectrum Beta Lactamases (Taneja and Sharma, 2008; Ankur Goyal, 2008; CLSI, 2014)

\section{Quality control}

Quality controls were performed using

Escherichia coli ATCC 25922

Negative control

Klebsiella pneumoniae ATCC 700603 Positive control

\section{Disk Diffusion Methods}

Disk diffusion test was done for all
Enterobacteriaceae isolates against cefotaxime $(30 \mu \mathrm{g})$, ceftriaxone $(30 \mu \mathrm{g})$, cefpodoxime $(10 \mu \mathrm{g})$ and ceftazidime $(30 \mu \mathrm{g})$ antibiotic disks for the screening of the isolates for potential ESBL production. Overnight incubation was done at $37^{\circ} \mathrm{C}$ after which the zone size was read as per CLSI recommendations for ESBL screening criteria (CLSI, 2014).

Phenotypic confirmatory tests or disc potentiation test

This test was done for all enterobacteriaceae isolates against Ceftazidime $(30 \mu \mathrm{g})$ antibiotic discs with and without clavunalic acid (10 $\mu \mathrm{g})$. These discs were placed on a Mueller Hinton agar plate inoculated with bacterial suspension equivalent to $0.5 \mathrm{McF}$ arland standards. Overnight incubation was done at $37^{\circ} \mathrm{C}$ after which the result was interpreted as follows.If the zone diameter of ceftazidime / clavulanic acid was augmented by $\geq 5 \mathrm{~mm}$ in comparison with ceftazidime alone was taken as ESBL positive (Nandagopal et al., 2015; Mandira Mukherjee et al., 2013; Umadevi et al., 2011; Babypadmini and Appalaraju, 2004).

Detection of ESBL Producers using Etest ESBL strip (Anandkumar Harwalkar et al., 2013; Revathi, 1997)

The ESBL E-strip was based on two gradients. One end of the strip contained ceftazidime $(0.5-32 \mu / \mathrm{ml})$, and the opposite end was impregnated with ceftazidime $(0.125-8 \mu \mathrm{g} / \mathrm{ml})$ and clavulanate $(4 \mu \mathrm{g} / \mathrm{ml})$. An overnight culture of the test organism on brain - heart infusion agar was suspended in saline to match the 0.5 McFarland standard turbidity. Then the suspension was used to inoculate a Mueller Hinton agar plate by swabbing the plate using a sterile cotton swab. The E-strip was placed on the plate after the plate was dried and it was incubated at $37^{0} \mathrm{C}$ overnight. 
For both the ends of the strip, the point of intersection between the inhibition eclipse and the edge of the E-strip was considered the minimum inhibitory concentration (MIC). A ceftazidime MIC / ceftazidime-clavulanate $\mathrm{MIC}$ ratio $\geq 8$ indicates the presence of ESBL enzymes as per the manufacturer's instruction manual.

Detection of ESBL gene (TEM, SHV and CTX-M) was done by using polymerase chain reaction (PCR) (Dallene et al., 2010).

\section{Results and Discussion}

Urine samples collected from 1000 Antenatal women without signs and symptoms of infection of the urinary tract were tested and 118 bacterial isolates were isolated, identified and analysed for their antibiotic sensitivity pattern. Resistant isolates were identified and studied for Methicillin Resistant Staphylococcus aureus (MRSA) and Extended Spectrum Beta Lactamases (ESBL) by various methods.

The observations were recorded and analysed. The results were as follows:

Out of the 1000 urine samples, 118 (11.8\%) were culture positive.(Fig-1). Among 118 isolates, total number of Gram negative bacilli were $78(66.10 \%)$ and total number of Gram positive cocci were 40(33.90\%) (Fig-2)

Mid stream clean catch urine specimens were collected from one thousand antenatal women without any symptoms of urinary tract infection who attended Obstetrics and Gynaecology outpatient department at Government Kilpauk Medical College Hospital, Chennai from January 2014 to June 2015. Urine samples were collected from pregnant women of different age groups, gravida and trimesters.

The culture positives with asymptomatic bacteriuria in pregnancy were $11.8 \%$. The culture positives were more in the 21-30 years age group, primigravida and in the first trimester. Gram negative bacilli were $78(66.10 \%)$, the predominant bacteria isolated in antenatal women with asymptomatic bacteriuria.

Escherichia coli was the major isolate constituting 54(45.76\%) followed by Staphylococcus aureus 21(17.8\%).In the study, antibiotic sensitivity of all Enterobacteriaceae and Pseudomonas aeruginosa showed $100 \%$ sensitivity to Imipenem and piperacillin/tazobactam. Amoxycillin showed less than $45 \%$ sensitivity to all the Gram negative isolates.

Staphylococcus aureus, Enterococcus faecalis and Staphylococcus saprophyticus showed $100 \%$ sensitivity to vancomycin. Among 21 Staphylococcus aureus, 17(80.95\%) were sensitive to amoxicillin-clavulanic acid, $16(76.19 \%)$ to nitrofurantoin and $9(42.85 \%)$ to cephalexin.

Out of 75 Gram negative bacilli, 6(8\%) were ESBL producers by both screening andphenotypic confirmatory test. Minimum inhibitory concentration (MIC) was done with E-strip containing ceftazidime and ceftazidime with clavulanic acid for the ESBL producers.

Of the 4 ESBL positive Escherichia coli, $3(75 \%)$ were positive and of the 2 ESBL positive Klebsiellapneumonia, 1(50\%) was positive showing a ceftazidime and ceftazidime/clavulanate MIC ratio of $\geq 8$. 
Table.1 Distribution of organisms $(n=118)$

\begin{tabular}{|l|c|}
\hline \multicolumn{1}{|c|}{ Organisms } & Percentage \\
\hline Escherichia coli & $54(45.76 \%)$ \\
\hline Staphylococcus aureus & $21(17.80 \%)$ \\
\hline Klebsiella pneumoniae & $19(16.10 \%)$ \\
\hline Staphylococcus saprophyticus & $10(8.45 \%)$ \\
\hline Enterococcus faecalis & $9(7.63 \%)$ \\
\hline Pseudomonas aeruginosa & $3(2.54 \%)$ \\
\hline Proteus mirabilis & $2(1.69 \%)$ \\
\hline
\end{tabular}

Out of the 118 isolates, Escherichia coli 54(45.76\%) was the predominant isolate followed by Staphylococcus aureus. Proteus mirabilis was the least common organism isolated 2(1.69\%).

Table.2 Antibiotic sensitivity pattern of Gram negative isolates $(\mathrm{n}=78)$

\begin{tabular}{|l|l|l|l|l|}
\hline \multicolumn{1}{|c|}{ Name of the Drug } & $\begin{array}{c}\text { Escherichi } \\
\text { a coli } \\
(\mathbf{n = 5 4 )}\end{array}$ & $\begin{array}{c}\text { Klebsiella } \\
\text { pneumoniae } \\
(\mathbf{n = 1 9 )}\end{array}$ & $\begin{array}{c}\text { Proteus } \\
\text { mirabilis } \\
(\mathbf{n = 2})\end{array}$ & $\begin{array}{c}\text { Pseudomonas } \\
\text { aeruginosa } \\
(\mathbf{n = 3})\end{array}$ \\
\hline Amoxycillin & $24(44.4) \%$ & $7(36.8 \%)$ & 0 & Not tested \\
\hline Amoxycillin/ Clavulanic acid & $46(85.2 \%)$ & $9(47.4 \%)$ & $1(50 \%)$ & $2(66.7 \%)$ \\
\hline Cotrimoxazole & $39(72.2 \%)$ & $11(57.9 \%)$ & $1(50 \%)$ & $2(66.7 \%)$ \\
\hline Cephalexin & $32(59.3 \%)$ & $7(36.8 \%)$ & 0 & Not tested \\
\hline Cefotaxime & $50(92.6 \%)$ & $17(89.5 \%)$ & $2(100 \%)$ & Not tested \\
\hline Ceftazidime & $50(92.6 \%)$ & $17(89.5 \%)$ & $2(100 \%)$ & $3(100 \%)$ \\
\hline Gentamicin & $35(64.8 \%)$ & $10(52.6 \%)$ & $1(50 \%)$ & $1(33.3 \%)$ \\
\hline Amikacin & $42(77.8 \%)$ & $15(79 \%)$ & $1(50 \%)$ & $1(33.3 \%)$ \\
\hline Norfloxacin & $30(55.6 \%)$ & $10(52.6 \%)$ & $1(50 \%)$ & $1(33.3 \%)$ \\
\hline Ofloxacin & $45(83.3 \%)$ & $13(68.4 \%)$ & $1(50 \%)$ & $2(66.7 \%)$ \\
\hline Nitrofurantoin & $48(88.9 \%)$ & $15(79 \%)$ & 0 & $3(100 \%)$ \\
\hline Piperacillin/ Tazobactum & $54(100 \%)$ & $19(100 \%)$ & $2(100 \%)$ & $3(100 \%)$ \\
\hline Imipenem & $54(100 \%)$ & $19(100 \%)$ & $2(100 \%)$ & $3(100 \%)$ \\
\hline
\end{tabular}

All the Gram negative bacilli were $100 \%$ sensitive to Piperacillin/Tazobactum and Imipenem. Nitrofurantoin showed 48(88.9\%) and 15(79\%) sensitivity to Escherichia coli and Klebsiellapneumoniae. Amoxycillin showed 24(44.4\%) sensitivity to Escherichia coli and 7(36.8\%) to Klebsiella pneumoniae.

Fig.1

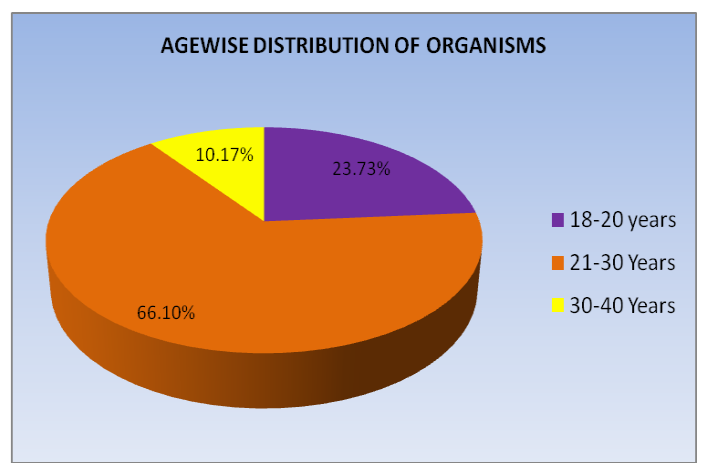


Table.3 Antibiotic sensitivity pattern of Gram positive organisms $(n=40)$

\begin{tabular}{|l|c|c|c|}
\hline Name of the Drug & $\begin{array}{c}\text { Staphylococcus } \\
\text { aureus }(\mathbf{n = 2 1})\end{array}$ & $\begin{array}{c}\text { Staphylococcus } \\
\text { saprophyticus }(\mathbf{n = 1 0})\end{array}$ & $\begin{array}{c}\text { Enterococcus } \\
\text { faecalis }(\mathbf{n}=9)\end{array}$ \\
\hline Amoxycillin & $8(38.09 \%)$ & $5(50 \%)$ & $3(33.30 \%)$ \\
\hline Amoxycillin/clavulanic acid & $19(90.47 \%)$ & $10(100 \%)$ & $6(66.66 \%)$ \\
\hline Cotrimoxazole & $10(47.62 \%)$ & $7(100 \%)$ & $5(55.55 \%)$ \\
\hline Cephalexin & $9(42.85 \%)$ & $7(70 \%)$ & Not tested \\
\hline Cefotaxime & $15(71.42 \%)$ & $8(80 \%)$ & Not tested \\
\hline Gentamicin & $10(47.62 \%)$ & $6(60 \%)$ & $5(55.55 \%)$ \\
\hline Amikacin & $15(71.42 \%)$ & $8(80 \%)$ & $6(66.66 \%)$ \\
\hline Norfloxacin & $9(42.85 \%)$ & $6(60 \%)$ & $6(66.66 \%)$ \\
\hline Ofloxacin & $17(80.95 \%)$ & $9(90 \%)$ & $8(88.88 \%)$ \\
\hline Nitrofurantoin & $16(76.19 \%)$ & $8(80 \%)$ & $7(77.77 \%)$ \\
\hline Vancomycin & $21(100 \%)$ & $10(100 \%)$ & $9(100 \%)$ \\
\hline
\end{tabular}

All the Gram positive cocci were $100 \%$ sensitive to Vancomycin. Staphylococcus aureus and Staphylococcus saprophyticus showed $79.19 \%$ and $80 \%$ sensitivity to Nitrofurantoin.

Staphylococcus aureus isolates were tested for Methicillin resistant Staphylococcus aureus using Cefoxitin disk. None of the Staphylococcus aureus isolates were Methicillin resistant Staphylococcus aureus.

By the screening test for ESBL and by phenotypic confirmatory test, 4(7.4\%) Escherichia coli and 2(10.5\%) Klebsiellaepneumoniae were identified as ESBL producers. None of the Proteus mirabilis isolates were positive for ESBL.

Table.4 Minimum inhibitory concentration of ESBL positive isolates using E-strip containing Ceftazidime and Ceftazidime/Clavulanic acid $(n=6)$

\begin{tabular}{|c|c|c|c|c|c|}
\hline S.NO & $\begin{array}{c}\text { Name of the } \\
\text { Organism }\end{array}$ & $\begin{array}{c}\text { Ceftazidime } \\
\text { MIC }\end{array}$ & $\begin{array}{c}\text { Ceftazidime + } \\
\text { Clavulanic Acid } \\
\text { MIC }\end{array}$ & Ratio & Result \\
\hline 1. & Escherichia coli & $>32$ & 0.25 & 128 & Positive \\
\hline 2. & Escherichia coli & 6 & 0.125 & 48 & Positive \\
\hline 3. & Escherichia coli & $>32$ & 0.25 & 128 & Positive \\
\hline 4. & Escherichia coli & 3 & 0.5 & 6 & Negative \\
\hline 5. & K.pneumoniae & 6 & 0.125 & 48 & Positive \\
\hline 6. & K.pneumoniae & 3 & 0.75 & 4 & Negative \\
\hline
\end{tabular}

Out of 4 ESBL positive Escherichia coli, 3(75\%) and of the 2 ESBL positive Klebsiella pneumoniae, $1(50 \%)$ showed $\geq 8$ times reduction in Minimum Inhibitory Concentration. 
Table.5 Gene identification in ESBL positive isolates for - TEM, SHV and CTX-M (n=6)

\begin{tabular}{|l|c|c|c|c|}
\hline Organism & $\begin{array}{c}\text { Total } \\
\text { Tested }\end{array}$ & $\begin{array}{c}\text { TEM } \\
\text { Positive }\end{array}$ & $\begin{array}{c}\text { SHV } \\
\text { Positive }\end{array}$ & $\begin{array}{c}\text { CTX -M } \\
\text { Positive }\end{array}$ \\
\hline Escherichia coli & 4 & 0 & 0 & 2 \\
\hline Klebsiella pneumoniae & 2 & 0 & 0 & 1 \\
\hline
\end{tabular}

Among 6 ESBL producers, 3 were positive for CTX-M gene. Of which 2 were Escherichia coli and 1 was Klebsiella pneumoniae. None of the isolates were positive for the TEM and SHV gene.

Fig.2

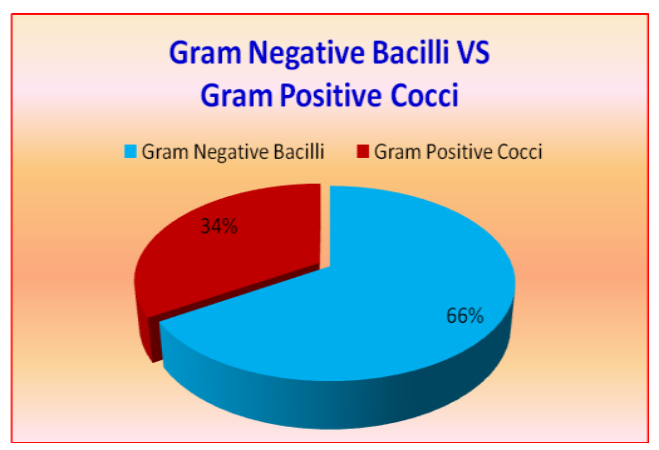

6 ESBL producing Enterobacteriaceae which were phenotypically confirmed as ESBL positives were subjected to genotypic test by Polymerase Chain Reaction (PCR). Three genes such as TEM, SHV and CTX-M associated with ESBL production were studied using the relevant primers for the corresponding genes. CTX-M was detected in $3(50 \%)$. In the present study, all the 21 Staphylococcus aureus isolates were Methicillin sensitive Staphylococcus aureus and none were found to be Methicillin resistant Staphylococcus aureus.

In conclusion, the present study showed high occurrence of asymptomatic bacteriuria in pregnant women which if not treated, might lead to various maternal and neonatal complications. Urine culture with clean catch mid stream urine is the most sensitive test for its detection preferably in the first trimester. All the sequelae of asymptomatic bacteriuria during pregnancy could be reduced by appropriate antimicrobial treatment early in pregnancy. Hence, screening and management of asymptomatic bacteriuria need to be incorporated as a routine antenatal care for an integrated approach to safe motherhood and newborn health.

\section{References}

Anand, K.B., Aggarwal, P., Kumar, S., Kapila, K. 2009. Comparison of Cefoxitin disk diffusion test, Oxacillin screen agar and PCR for Mec A gene for detection of MRSA. Indian J. Med. Microbiol., 27(1): 27-29

Anandkumar Harwalkar, Jagadeesh Sataraddi, Soham Gupta, Raksha Yoganand, Achut Rao, et al. 2013. The detection of ESBL producing Escherichia coli in patients with symptomatic urinary tract infections using different diffusion methods in a rural setting. J. Infection and Public health, 6:108-114. 
Ankur Goyal, Amit Prasad, Ujjala Ghoshal, K.N. Prasad. 2008. Comparison of disk diffusion, disk potentition and double disk synergy methods for detection of extended spectrum beta lactamases in Enterobacteriaceae. Indian J. Med. Res., 128: 209-211.

Annie Rajaratnam, Neha Maria Baby, Thomas, S., Kuruvilla, Santhosh Machado. 2014. Diagnosis of asymptomatic bacteriuria and associated risk factors among pregnant women in Mangalore, Karnataka, India. J. Clin. Diagn. Res., 8(9): OC23-OC25.

Babita, Sanjeev Suman, Shankar Prakash. 2013. Hospital Based Study For Asymptomatic Bacteriuria In Pregnant Women. J. Evol. Med. Dent. Sci., 2(44): 8574-8577.

Babypadmini, S., B. Appalaraju. 2004. Extended spectrum beta-lactamases in urinary isolates of Escherichia coli and Klebsiella pneumonia- Prevalence and susceptibility pattern in a tertiary care hospital. Indian J. Med. Microbiol., 22(3): 172-174.

Bauer, A.W., Kirby, W.M.M., Sherris, J.C., Tuck, M. 1996. Antibiotics susceptibility testing by standardized single disc method. Am. J. Clin. Pathol., 45: 493-6.

Chandel Lata, R., Kanga Anil, Thakur Kamlesh, Mokta Kiran, K., Sood Anuradha, et al. 2012. Prevalence of pregnancy associated asymptomatic bacteriuria: A study done in a Tertiary care hospital. The J. Obstetrics and Gynecol. India, 62(5): 511-514.

Clinical and Laboratory Standard Institute. 2014. Performance standards for antimicrobial susceptibility testing; $24^{\text {th }}$ informational supplement. CLSI document M100-S24. Clinical and Laboratory Standard Institute, Wayne, PA.

Dallene, C., Da Costa, A., Decre, D., Favier, C., Arlet, G. 2010. Development of a set of multiplex PCR assays for the detection of genes encoding important betalactamases in Enterobacteriaceae. $J$. Antimicrob. Chemother., 65: 490-495.

Gayathree, L., Shetty, S., Deshpande, S.R., Venkatesha, D.T. 2010. Screening for Asymptomatic bacteriuria in pregnancy: An evaluation of various screening tests at the Hassan District Hospital, India. J. Clin. Diagn. Res., (4): 2702-2706.

Graham, J.C., A. Galloway. 2001. The laboratory diagnosis of urinary tract infection. J. Clin. Pathol., 54: 911-919.

Jeyaseelan Senthinath, T., P. Chitra Rajalakshmi, R. Keerthana, R.S.Vigneshwari, P.Revathi, et al. 2013. Prevalence of asymptomatic bacteriuria among antenatal women in rural tertiary care hospital, Tamilnadu, India. Int. J. Curr. Microbiol. App. Sci., 2(1): 80-85.

Kheya Mukherjee, Saroj Golia, Vasundha, C.L., Babita, Debojyoti Bhattacharjee, et al. 2014. A study on asymptomatic bacteriuria in pregnancy: prevalence, etiology and comparision of screening methods. Int. J. Res. Med. Sci., 2(3): 1085-1091.

Lindsay, E., Nicolle. 2003. Asymptomatic bacteriuria When to screen and when to treat. Infect. Dis. Clin. N. Am., 17: 367394.

Mandira Mukherjee, Shreya Basu, Sandip kumar mukherjee, Monalisa Majumder. 2013. Multidrug- Resistance and extended spectrum beta- lactamase production in Uropathogenic E. coli which were isolated from hospitalised patients in Kolkata, India. J. Clin. Diagn. Res., 7(3): 449-453.

Nandagopal, B., S. Sankar, K. Sagadevan, H. Arumugam, M.V. Jesudason, et al. 2015. Frequency of Extended spectrum betalactamase producing urinary isolates of Gram-negative bacilli among patients seen in a multispeciality hospital in 
Vellore District, India. Indian J. Med. Microbiol., 33(2): 282-285.

Niranjan, V., Malini, A. 2014. Antimicrobial resistant pattern in Escherichia coli causing urinary tract infection among inpatients. Indian J. Med. Res., 139, June; pp 945-948.

Rajshekhar, D., Kerure, Umashanker. 2013. Prevalence of Asymptomatic bacteriuria among pregnant women in a tertiary care hospital, Int. J. Scientific Res. Publications., 3(11): 1-4.

Raksha, R., H. Srinivasa, R.S. Macaden. 2003. Occurence and characterisation of uropathogenic Escherichia coli in urinary tract infections. Indian J. Med. Micribiol., 21(2):102-107.

Raul Raz. 2003. Asymptomatic bacteriuria. Clinical significance and management. Int. J. Antimicrobial agents, 22; S45-S47.

Revathi, G. 1997. Detection of Extended spectrum Beta Lactamases using E-Test ESBL Strip. Indian J. Med. Microbiol., 15(2): 69-71.

Santogita Jain, Jaydev Pandya, Sanjay Mehta, Anil Jain, Kunjan Kikani, et al. 2013. Evaluation of asymptomatic bacteriuria in antenatal women at $\mathrm{Cu}$ Shah Medical College and Hospital, Surendranagar, Gujarat. Int. J. Med. Sci. Public Health, 2(4): 1021-1023.

Shruthi, N., Ravikumar, Ravish kumar. 2012. Phenotypic study of virulence factors in Escherichia coli isolated from Antenatal cases, catheterised patients, and faecal flora. J. Clin. Diagn. Res., 6(10): 16991703.

Sudha Birader Kerure, Rajeswari Surpur, Sheela S Sagarad, Sneha Hegadi. 2013. Asymptomatic bacteriuria among pregnant women. Int. J. Reproduction, Contraception, Obstetrics and Gynecol., 2(2): 213-216.

Sujatha, R., Manju nawani. 2014. Prevalence of asymptomatic bacteriuria and its antibacterial susceptibility pattern among pregnant women attending the antenatal clinic at Kanpur, India. J. Clin. Diagn. Res., 8(4): DC01-DC03.

Sushama, S., Thakre, Supriya, S., Dhakne, Subash, B., Thakre, Amol, D., Thakre, Suresh, M., Ughade, et al. 2012. Can the Griess Nitrite test and a Urinary pus cell count of $\geq 5$ cells per micro litre of urine in pregnant women be used for the screening or the early detection of urinary tract infections in rural India. $J$. Clin. Diagn. Res., 6(9): 1518-1522.

Taneja, N., Sharma, M. 2008. ESBLs detection methods in clinical microbiology: Why and How. Indian J. Med. Res., 127: 297-300.

Umadevi, S., Kandhakumari, G., Joseph, N.M., Kumar, S., Easow, J.M. et al. 2011. Prevalence and antimicrobial susceptibility pattern of ESBL producing Gram negative bacilli. J. Clin. Diagn. Res., 5(2): 236-239.

\section{How to cite this article:}

Hemalatha, S., K.V. Leela, Radhika Katragadda, Thyagarajan Ravinder, P. Hema Suganya and Padmanaban, S. 2017. Isolation of Bacterial Pathogens and Detection of MRSA and ESBL Producers causing Asymptomatic Bacteriuria in Antenatal Women. Int.J.Curr.Microbiol.App.Sci. 6(1): 518-526. doi: http://dx.doi.org/10.20546/ijcmas.2017.601.062 